\title{
IDENTIDADES, PARTIDOS, CRISTIANISMO GLOBAL NA ANÁLISE SOBRE EVANGÉLICOS ${ }^{1}$
}

\author{
IDENTITIES, POLITICAL PARTIES AND GLOBAL CHRISTIANITY IN THE
} ANALYSIS OF EVANGELICAL CHRISTIANS

\section{Christina Vital da Cunha ${ }^{2}$}

A riqueza dos comentários feitos ao artigo "Irmãos contra o império" é notável. O desafio nesta tréplica é dialogar com eles equilibrando objetivos, potenciais e limites da proposta do texto original com as possibilidades analíticas que meus colegas salientaram em suas contribuiçôes. Sem dúvida, este exercício guarda uma dimensão de "sociologia à queima roupa"3. Dado o volume de questóes e problemas públicos que se pronunciam, cientistas sociais são convocados a explicar contextos, arranjos e situaçóes no calor dos acontecimentos em lives e variados programas televisivos e radiofônicos. $\mathrm{O}$ empreendimento é louvável. Nem sempre tem sucesso, mas o fenômeno do intelectual youtuber e influencer em distintas redes sociais é uma realidade. Wright Mills, sociólogo americano, tradutor de Weber, pesquisador de classes sociais, trabalho e artes, em seu clássico "A imaginação sociológica", publicado ao final dos anos 1950, anunciava o papel central que os cientistas sociais teriam daquele século em diante para a compreensão pública das mais diversas situaçóes sociais combatendo medos e apatias. Em sua reflexão, a

${ }^{1}$ Como Citar: VITAL DA CUNHA, Christina. Identidades, partidos, cristianismo global. Debates do NER, Porto Alegre, ano 21, v. 39, p. 157-171, 2021.

2 Professora Associada do Departamento de Sociologia e do Programa de Pós-Graduação em Sociologia e coordenadora do LePar-Laboratório de Estudos Sócio Antropológicos em Política, Arte e Religião na Universidade Federal Fluminense, Brasil. E-mail: chrisvital10@gmail.com. ORCID: https://orcid.org/0000-0003-4867-1500..

${ }^{3}$ Expressão muito utilizada por Flávia Rios, minha amiga e colega de departamento de Sociologia na UFF, socióloga e pesquisadora das relaçóes étnico-raciais, coordenadora do Núcleo de Estudos Guerreiro Ramos (N.E.G.R.A). 
literatura teve um lugar especial para identificação de questóes presentes nas sociedades até então, mas, aos cientistas sociais, caberia interpretar os fenômenos e orientar a ação. De modo um pouco mais matizado, antropólogos sugeriram que nos caberia contribuir com versôes de segunda ou terceira mão (Geertz, 2008 [1978]) sobre acontecimentos. Não haveria, portanto, um domínio na produção das interpretaçóes e os bons estudos revelam cada vez mais a polifonia que os constituíram. Nesta tréplica, pretendo me pronunciar em relação aos comentários trazendo sempre as situaçóes e atores, ao lado da reflexão teórico metodológica, quando necessário.

Os comentadores de "Irmãos contra o império" são pesquisadores cujas carreiras são marcadas por extensa, séria e criativa produção. São homens e mulheres, de geraçôes, formaçóes, universidades, nacionalidades distintas e que fizeram aportes a partir de seus pertencimentos, inquietaçóes políticas e acadêmicas. Pela leitura atenta, perspicaz e generosa agradeço a eles, assim como ao também querido e admirável editor deste Debate por esta e tantas outras interlocuçóes. A ele, aos demais editores da revista Debates do NER e sua equipe, parabenizo pela eficiência e gentileza nos contatos, assim como por demonstrarem ânimo renovado em manterem este importantíssimo periódico em um mercado editorial brasileiro e internacional cada vez mais competitivo e, por vezes, hostil. Vida longa à Debates do NER!

\section{QUEM SÃO OS EVANGÉLICOS “DE BASE”?}

Ao menos três grandes questóes foram exploradas pelos comentadores em suas réplicas à discussão inicial por mim proposta: a questão da identidade, da política partidária e da influência dos Estados Unidos da América no cristianismo global, com destaque para o brasileiro. Em linhas gerais, no artigo "Irmãos contra o império" tivemos como objetivo refletir sobre um momento de reorganização de grupos e segmentos de esquerda no Brasil, através de dados sobre a participação de evangélicos nas eleiçóes 2020. As questôes sobre identidade religiosa, racial, sexual e de gênero foram destacadas 
na análise porque compunham meios de apresentação de si de ativistas e candidatos acompanhados na pesquisa. Meu olhar recaiu não propriamente sobre a construção das identidades sociais reais ou virtuais (Goffman, 1980) deles, mas sobre as performances em torno dessas identidades. Sendo assim, havia um interesse especial sobre como as identidades eram acionadas naquele contexto eleitoral. Se, por um lado, a revelação destas identidades produzia coesão, aproximação, reforçava (ou buscava reforçar) o capital político de atores, por outro lado, essas mesmas identidades emergiam como formas de acusação de uns contra outros e de (re) produção de estigmas.

No artigo original, acompanhamos coletivos e candidaturas de evangélicos e evangélicas identificando estratégias de visibilidade que envolveram, necessariamente, produção de narrativas, estéticas, articulações para dentro e fora do grupo religioso, escolha de partidos etc. Os integrantes dos coletivos anunciavam as "questóes identitárias" por eles defendidas no âmbito da política partidária, eletiva, como próprias de suas lutas cotidianas. Se deixei claro ao longo do texto que a escolha do Movimento Bancada Evangélica Popular e do Cristãos Contra o Fascismo estabelecia um viés na medida em que se tratava, na maioria dos casos ali anunciados, de integrantes de movimentos sociais há mais ou menos tempo, com maior ou menor intensidade, alguns com formação superior, isso não deveria lhes projetar como pessoas distantes irremediavelmente da maioria evangélica também chamada de "base". Esta reflexão nos leva a outra. O que chamamos de base evangélica? Atribui-se a ela uma "identidade"? A busca pela voz "da base", pelo entendimento "da base" não significaria, na atualidade, uma espécie de fetiche de esquerda (acadêmica ou não)? Reconhecer o que é "a base" evangélica posiciona o ator detentor deste (suposto) conhecimento como proprietário de um conjunto de informaçóes que o qualificam como um expert no que é ser evangélico no Brasil? Recordo-me bem das leituras de Novaes (1985; 1990) e Almeida (2006) realizadas entre o mestrado e o doutorado acentuando as várias formas possíveis de ser evangélico. A consideração radical desta assertiva derruba limites morais e cânones de área convidando-nos a observar a vida social e as composiçóes e interfaces que 
evangélicos elaboram em seus cotidianos - nos fazendo refletir, inclusive, sobre aproximaçóes entre cristianismo evangélico e traficantes de drogas (Vital da Cunha, 2015). Steil e Toniol (2013) apresentam como a diversidade de abordagens sobre religião se estabelece nas ciências sociais, fruto de mudanças variadas seja no campo religioso, seja no campo acadêmico em termos das renovações em sua composição social aportando outros olhares e interesses. Indubitavelmente o crescimento percentual de evangélicos no país e sua busca singular por visibilidade (Giumbelli, 2013) obriga cientistas sociais da religião (ou não) a investigarem esses atores valorizando suas diferentes faces e modos de atuação.

Dados do Instituto DataFolha, veiculados em janeiro de 2020, revelam que os evangélicos no Brasil conformam 31\% da população. Deste total, 58\% são mulheres, 59\% são negros (pretos e pardos), 62\% tem até 44 anos de idade, $15 \%$ tem ensino superior (muito acima da média nacional que está em 8,7\%, segundo dados do IBGE de 2019), 48\% recebe até dois salários mínimos por mês. Quando o recorte recai sobre os que se autodeclaram fiéis de alguma denominação considerada neopentecostal, o número de mulheres chega a 69\%. Com base nestas estatísticas poderíamos então traçar um perfil sobre a "base evangélica" como feminina, predominantemente com ensino médio ( $48 \%$ do total de evangélicos concluiu todo o ensino básico), majoritariamente negra. Informaçóes demográficas ajudam a compor o mosaico do evangelismo no país, mas são insuficientes para compreendermos a miríade de possibilidades que se anunciam em torno de cada uma das variáveis desses estudos. Do ponto de vista sócio antropológico, como podemos falar sobre quem são "evangélicos de base" a partir destes dados? Os limites são inúmeros, deixando esse empreendimento em fundaçôes movediças. A recente e excelente etnografia feita por Juliano Spyer, acompanhando evangélicos em uma periferia na Bahia, nos fornece muitos casos e dados importantes para refletirmos sobre a relação desses atores sociais com as questóes econômicas, sociais, de gênero, moradia, raça, sexualidade. Mas nos gabarita a entender "a base” evangélica no Brasil? Talvez não. Ricas e abundantes pistas são oferecidas no estudo de Spyer, a mais rica delas 
pode ser justamente a que indica para a diversidade de modos de compor a maioria demográfica dos evangélicos no Brasil, renovando o que já registrou a bibliografia clássica sobre o tema nas ciências sociais da religião no país.

O fetiche político (e às vezes até acadêmico) em torno da "base evangélica” não pode ser resolvido quando pensamos nessa maioria como um monólito. No entanto, devemos considerá-la analiticamente quando estão sendo produzidas performances pelos próprios atores em situação (Gluckman, 1987) em torno da "identidade de base". Evidentemente, o calor da política exige respostas mais gerais, menos matizadas, mas é preciso ter cautela no que diz respeito à produção acadêmica.

Do ponto de vista demográfico, a maioria dos candidatos e ativistas entrevistados na pesquisa sobre as eleiçóes 2020, apresentados no artigo "Irmãos contra o império", comporiam o que se convencionou chamar de "base evangélica". Mesmo os que têm formação universitária poderiam se considerar como "base" ou poderiam ser considerados assim por estudiosos ou políticos na medida em que partilham de inúmeras condiçóes de vida semelhantes à base da pirâmide social (evangélica ou não). Ocupam determinadas posiçóes na estrutura social e mesmo a visibilidade que vários deles alcançam nas redes sociais não lhes exime dos condicionantes sociais e materiais que a estrutura impóe. Seus agenciamentos, sem dúvida, resultaram na projeção de alguns deles como líderes de movimentos, ativistas reconhecidos nacional e internacionalmente e isso pode lhes conferir outro lugar social e econômico, mas não necessariamente. Talvez o catapultar que algumas redes universitárias proporcionam para eles, oferecendo a mobilidade que os laços fracos possibilitam (Granovetter, 1973), seja real para alguns, mas não é todo "pertencimento" universitário que viabiliza o acesso a redes e mobilidade social.

Quando se fala que evangélicos que se autoapresentam como progres$\operatorname{sistas}^{4}$ ou de esquerda, não seriam "representantes" da maioria, que estão

\footnotetext{
${ }^{4}$ No artigo apresento as inúmeras e às vezes conflitantes percepçôes de evangélicos sobre o que é ser "progressista”. Juliano Spyer apresentou em seus comentários uma pesquisa
} 
distantes da base, qual o subtexto? A reflexão proposta por Alexandre Brasil em seus comentários sobre uma tensão entre representatividade indica vias para refletir sobre (supostos ou não) distanciamentos entre candidatos de esquerda e a maioria evangélica. Mas minha intuição é que o subtexto, o posicionamento prévio de muitos acadêmicos, políticos de esquerda e elites é que a maioria evangélica (tratados como mônadas) é conservadora (como se isso fosse autoexplicativo e exclusivo deste segmento religioso), tradicional. Neste enquadramento, serem progressistas ou de esquerda os projetaria para longe das "bases" de modo irreconciliável. O mais fascinante nesse olhar para a estrutura, para as bases sociais, parece-me, é observar o número crescente de evangélicos engajados em instituiçôes ou que se formam em uma "cultura pentecostal" estabelecendo valores morais de referência através deste universo religioso (Vital da Cunha, 2018; 2021) em diálogo com a cultura e as expectativas sociais envolventes atualizando-as, como bem lembrou Spyer com os dois casos que trouxe em seus comentários. Nessas atualizaçóes, é possível que vejamos muitos pontos de contato entre a maioria evangélica e a diversidade a partir da qual a própria "esquerda evangélica” se apresenta. $\mathrm{O}$ volume e a capilaridade das mudanças vão sendo acompanhadas em sua complexidade ao longo de estudos dispostos a conectar a dimensão religiosa com outras tantas que compóem a vida social de qualquer indivíduo.

O reconhecimento da diversidade de modos de ser dessa "maioria evangélica" é importante para compreendermos as disputas por legitimidade internas ao grupo. Deste modo, entre as candidaturas acompanhadas e os entrevistados na pesquisa, a dimensão da luta diária envolve, além de questôes de classe social, raça, gênero e sexualidade, uma disputa interna por legitimidade sobre suas identidades religiosas. Em recente postagem no Twitter, Vinícius Lima, candidato a vereador em São Paulo, desabafou sobre seu cansaço por viver em uma constante situação de descrédito em relação a

sob sua coordenação para o Instituto Idea Big Data (2018) apresentando outro conjunto de referências que vão ao encontro das que apresento detidamente em "Irmãos contra o império".

Debates do NER, Porto Alegre, ANo 2 I, N. 39, P. I 57-I7 I, JAN./JUl. 202 I 
ser evangélico e ser de esquerda. Em suas palavras: "Fazer política à esquerda sendo evangélico é cansativo. É sempre um lugar de prova. Provar para a sua igreja o seu amor à Jesus (sic) e provar para o seu grupo político a sua luta. $\mathrm{O}$ caminho menos cansativo é entender que esse lugar é solitário e fazer o que tem que ser feito: servir" ${ }^{\prime}$. Pensando no campo evangélico tal como nos sugere a teoria prática de Bourdieu, líderes evangélicos, formados por empresários e/ou elites econômicas as mais variadas - do setor imobiliário ao jurídico -, afirmam que ser evangélico é ser de direita ou conservador. Mencionei estes esforços em diversas postagens e vídeos de políticos evangélicos e líderes midiáticos em "Irmãos contra o império". Mais recentemente, em 08 de maio de 2021, o antigo Ministro da Educação, Abraham Weintraub, fez um tweet sobre a iniciativa de integrantes da Bancada Evangélica Popular em lançarem um observatório para monitorar representantes nos três Poderes, conforme noticiado na Folha de São Paulo. O ex-ministro comentou, em seu Twitter: "Mamíferos que botam ovos, peixes que voam e evangélicos de esquerda. A fiolha di sun paulx inventa cada uma... Leitor da Bíblica de esquerda? Deve ser bonito como um ornitorrinco". Essa disputa por legitimidade entre os que são progressistas ou de esquerda tem um desafio para além do teológico: a polarização recente do debate público. Esta polarização é destruidora das mediações tão fundamentais em diálogos, para o exercício pleno da democracia, enfim, como nos chama atenção João Cezar Rocha (2021). Ou seja, se por um lado denunciamos o olhar para a "maioria evangélica" como "naturalmente" conservadora, reconhecemos o domínio dessa narrativa no campo evangélico (e para fora dele), mas insistimos na necessidade de olharmos para as várias formas de experimentar essa identidade e, igualmente, a fluidez, a dinâmica desses processos existenciais e sociais. É preciso avançar nas reflexôes considerando as contradições, controvérsias e arranjos situacionais.

Em consideração ao comentário de Marina Lacerda, diria que o uso da expressão "Irmãos contra o império" no título do artigo se justifica pela

\footnotetext{
${ }^{5}$ Postagem no Twitter de 15 de abril de 2021. Acesso no mesmo dia.
} 
força interna que a noção assume para o grupo de atores acompanhados na pesquisa com sentidos diversos, mas convergentes entre eles. Por um lado, assume uma dimensão de luta contra o sistema capitalista (tal como Ariovaldo Ramos apresenta em entrevista concedida à pesquisa, dimensão que chamou atenção de Marina Lacerda em seus comentários) e também teológica na afirmação do Reino de Deus que se oporia ao Império pela força da mensagem bíblica que o primeiro expressa de amor, solidariedade e união. Uma forma de luta sócio teológica que perpassa a trajetória dos atores acompanhados na pesquisa e que, em si, aponta também para disputas, contradiçōes, controvérsias.

\section{A INFLUÊNCIA NORTE-AMERICANA NO EVANGELICALISMO BRASILEIRO}

Os questionamentos levantados acima sobre uma conexão por vezes imediata, singular e inescapável da maioria evangélica com o conservadorismo político e moral não deixa de considerar a influência que o evangelismo norte-americano (em sua face conservadora) teve e tem entre este grupo religioso no Brasil. Em diversas passagens do texto, menciono tais aproximaçôes indicando autores que o fizeram com excelência. Maria das Dores Campos Machado faz uma interessante reflexão dando lugar à memória para a compreensão de discursos e práticas de evangélicos no passado (antes e durante a Ditadura Militar no Brasil) e na atualidade, incidindo em revisóes discursivas que ocorrem não só entre evangélicos de esquerda, mas também de direita no país. Os conflitos por representação política (entre direita e esquerda evangélica, e também católica) teriam o sentido de uma disputa por hegemonia cultural. Em linha semelhante, Alexandre Brasil e Marina Lacerda referem-se a seus próprios trabalhos e de outros pesquisadores enfatizando as conexôes entre cristianismo branco norte-americano, conglomerados econômicos e política eleitoral nos EUA com forte influência sobre 
o evangelismo no Brasil, sobretudo durante a campanha e a presidência de Jair Bolsonaro.

Segundo Rolim (1985), fartamente citado por Lacerda em seus comentários, predominou no país a marca do pentecostalismo dos "brancos estadunidenses" que "deu particular ênfase ao batismo no Espírito Santo, na glossolalia, aos dons de cura e de falar em línguas estranhas" (Rolim, 1985, p. 70). Na mesma citação, o autor salienta que a visão dos crentes brancos norte-americanos era diferente da dos negros pentecostais. Para estes, práticas religiosas e sociopolíticas eram indissociáveis. No artigo "Irmãos contra o império" o destaque recaiu justamente sobre os evangélicos que associam lutas cotidianas por sobrevivência à dimensão política e também religiosa ${ }^{6}$. Talvez suas performances, estéticas e gramáticas não sejam majoritárias no segmento evangélico no Brasil, mas se somam situacionalmente às suas vozes em uma ou outra agenda em especial. Na pesquisa que realizo acompanhando associaçóes de juristas evangélicos, as açóes e performances se assemelham em muito aos evangélicos estadunidenses destacados nos comentários de Alexandre Brasil Fonseca e Marina Lacerda. Outros trabalhos serão publicados resultantes da pesquisa do ISER sobre as eleições 2020 destacando este mainstream da política evangélica no Brasil e em alguns deles, sem dúvida, esta discussão será retomada em profundidade em razão propriamente dos atores que são foco do estudo.

${ }^{6}$ Inspirada na obra "O reino e a glória: Uma genealogia teológica da economia e do governo”, do filósofo italiano Giorgio Agamben (2011), Mariana Côrtes (2020) faz uma bela discussão sobre a existência de uma zona de indistinção entre privado e público, ou, entre oikos e polis, nos termos do autor para evangélicos considerados de direita ou conservadores no Brasil. Argumento que esta zona de indistinção a qual Côrtes se refere, a contiguidade entre esferas, vale também para o caso de evangelicos de esquerda ou progressistas por mim acompanhados na pesquisa, embora com interesses e resultados distintos dos chamados conservadores.

Debates do NER, Porto Alegre, ANo 2 I, N. 39, P. I 57-I7 I, JAN./JUl. 202 I 


\section{SOBRE A DISPUTA PARTIDÁRIA E RELIGIOSA}

A questão partidária foi outra dimensão destacada nos comentários ao artigo "Irmãos contra o império". Em publicação anterior (Vital da Cunha, Lopes e Lui, 2017), apresentamos disputas político partidárias e religiosas entre o Partido Social Cristão (PSC) e o então Partido Republicano Brasileiro (PRB), atual Republicanos, e, respectivamente, Assembleia de Deus e Igreja Universal do Reino de Deus. Nas eleiçôes 2014, líderes partidários anunciaram seu anseio em torno do crescimento das duas legendas. $\mathrm{Na}$ ocasiāo, o PRB teve um aumento significativo em sua bancada saindo de 10 deputados federais eleitos em 2010 para 21 em 2014, enquanto o PSC decresceu de 17 eleitos em 2010 para 14 deputados federais eleitos em 2014. A questáo dos partidos de viés religioso foi abordada nesta mesma revista sobre as eleiçóes municipais que antecederam as que tratei em meu artigo (Carvalho e Oro, 2017; Freston, 2017). As reflexôes ali contidas são importantes e merecem atualização diante das inúmeras movimentaçóes e tentativas continuadas de formação de grupos partidários com bases religiosas.

Em seus comentários, Alexandre Brasil investe boa parte de sua atenção ao tema abordando estratégias denominacionais e partidárias no passado e no presente. Se no passado nossa atenção se voltou às disputas entre legendas que podem ser consideradas fisiológicas ou de direita, meu interesse recai sobre a recente movimentação de partidos de esquerda na direção do diálogo e da ampliação de candidaturas evangélicas entre aquelas com visibilidade e significativo investimento partidário. O caso do Partido dos Trabalhadores (PT) talvez seja o mais emblemático nas eleiçóes de 2020, ao lado do Partido Socialismo e Liberdade (PSOL). Geter Borges, um dos principais articuladores do Núcleo de Evangélicas e Evangélicos do PT, lançado em São Paulo em 2019, é militante de esquerda de grande expressão. Religioso Batista, foi assessor da bancada do PT na Câmara dos deputados e foi secretário executivo do Movimento Evangélico Progressista (MEP) para o período de 2003-2007, coincidindo com o primeiro mandato do PT na presidência da República com Luiz Ignácio Lula da Silva. É nossa pretensão refletir 
de modo mais detido sobre esta questão em produção futura resultado da pesquisa ISER - LePar/UFF.

A leitura de David Lehmann de "Irmãos contra o império" chama atençâo para a laicidade, tema candente na agenda pública brasileira desde o final do século XIX, mas que assumiu grande visibilidade a partir de meados dos anos 1990. Para ele, uma questão importante tratada em meu texto seria a separaçáo que os candidatos e ativistas entrevistados fazem entre serem religiosos e fazerem da política um meio de defesa dos valores próprios de seu grupo religioso e de suas igrejas. Em suas palavras: "Faço menção do tema para aclarar que laicidade não quer dizer que discursos religiosos náo devem aparecer na vida política, mas sim que instituiçóes religiosas e suas normas náo devem ter um papel em decisôes técnicas ou burocráticas do Estado" (Lehmann). Considero esta expressiva do modo a partir do qual evangélicos de esquerda ou progressitas buscaram legitimar publicamente até aqui suas candidaturas e mandatos. Entre os chamados evangélicos conservadores, pelo contrário, suas presenças na política se justificaram, no mais das vezes, por serem defensores privilegiados de valores cristáos, ainda que esses conflitem com as leis republicanas. Destaco a assertiva de Lehmann também porque esta me remeteu imediatamente a uma formulaçáo de Pierucci em "De olho na modernidade religiosa", editorial de abertura do Dossiê Sociologia da Religião, na revista Tempo Social (2008). Nela, o autor faz uma ode à secularizaçáo. Sem temer ser diretivo demais, pecar contra "relativizações necessárias", ele disse:

Em matéria de modernidade secular, se eu puder escolher, fico com a "secularização do Estado". Politicamente convencido de que pessoas livres (re)querem Estados laicos, bato-me já há algum tempo (desde 1998 pelo menos) pelo seguinte desideratum: oxalá os cientistas sociais e historiadores passássemos pouco a pouco a incorporar, majoritária e rotineiramente, a idéia de secularização do Estado como um componente crucial, se não o mais crucial de todos, da conceituação histórico-social de uma secularização da qual não pode abrir mão toda modernidade que se preze (Pierucci, 2008, p. 12). 
Comecei esta réplica falando sobre a convocação contemporânea de cientistas sociais para se posicionarem sobre os mais variados problemas públicos. Fecho com esse querido (e também polêmico) sociólogo que na história recente das ciências sociais nunca temeu esse papel. Suas contribuiçôes ao debate sobre religião, política e Estado são notáveis referências a inspirarem geraçóes posteriores que, em seus estudos e posicionamentos, buscam fontes para a compreensão de arranjos e dinâmicas sociais que persistem na memória e nas atualizaçóes discursivas de atores em campo, como lembrou Maria das Dores Campos Machado.

O que não foi possível comentar nesta tréplica fica como promessa de diálogo a ser retomada em outras publicaçôes resultantes deste trabalho coletivo de pesquisa. Mais uma vez, obrigada.

\section{REFERÊNCIAS}

ALMEIDA, Ronaldo. A expansão pentecostal: circulação e flexibilidade. In: TEIXEIRA, Faustino; MENEZES, Renata (Org). As religióes no Brasil: continuidades e rupturas. Petrópolis, RJ: Vozes, 2006.

ALVITO, Marcos. Nós contra o mundo. Pentecostais ajudam na inserção social dos mais pobres, mas criam uma guerra espiritual: fora da igreja só existe o diabo. Revista de História do Museu Nacional 87(8), p. 27-9, 2012. CARVALHO JUNIOR, Erico. ORO, ARI PEDRO . Eleições municipais 2016: religião e política nas capitais brasileiras. Debates do NER, n. 32, p. 15-68, 2017.

CONTINS, Marcia. Subjetividade e alteridade: os pentecostais negros no Brasil e nos Estados Unidos. Logos, 11, n. 2, p. 24, 2015.

CÔRTES, Mariana. Entre a danação e a glória: o ministério de flordelis e o problema da oikonomia cristá. Debates do NER, Porto Alegre, ano 20, n. 38, p. 83-95, 2020. 
COWAN, Benjamin Arthur. "Nosso Terreno": crise moral, política evangélica e a formação da "Nova Direita" brasileira. Varia História, 30, p. 101-125, 2014 .

GEERTZ, Clifford. A interpretação das culturas / Clifford Geertz. - 1.ed., IS. reimpr. - Rio de Janeiro: LTC, 2008.

GIUMBELLI, Emerson. Cultura Pública: evangélicos y su presencia en la sociedad brasileña. Sociedad y Religión, v. 23, pp. 13-43, 2013.

GLUCKMAN, Max. Análise de uma situação social na Zululândia moderna. In: BIANCO, Bela Feldman (Org.) Antropologia das Sociedades Contemporâneas. São Paulo: Global, 1987

GOFFMAN, Erving. Estigma e identidade social. In: Estigma - notas sobre a manipulação da identidade deteriorada. Rio de Janeiro: Zahar Editores, $3^{\mathrm{a}}$ ed., 1980.

GRANOVETTER, Mark S. The Strength of Weak Ties. The American Journal of Sociology, Vol. 78, No. 6, p. 1360-1380, 1973.

FERREIRA, Jorge; REIS FILHO, Daniel Aarão (Org.). As esquerdas no Brasil. $2^{\circ}$ vol.: Nacionalismo e reformismo radical, 1945-1964. 1. ed. Rio de Janeiro: Civilização Brasileira, 2007.

FONSECA, Alexandre Brasil. Discursos evangélicos de uma nova Direita Cristã à Brasileira. In: SOLANO, Esther (Org.). Brasil em colapso. São Paulo: Editora Unifesp, 2019. p. 105-120.

FRESTON, Paul. A RELIGIÃO E AS ELEIÇÕES MUNICIPAIS BRASILEIRAS DE 2016: A VERDADEIRA NOVIDADE. Debates do NER, Porto Alegre, ano 18, n. 32, p. 81-86, jul./dez. 2017.

NOVAES, Regina. A divina política: notas sobre as relaçôes delicadas entre religião e política. REVISTA USP, São Paulo, n. 49, p. 60-81, 2001.

NOVAES, Regina. Ouvir para crer: os racionais e a fé na palavra. Religião e sociedade, v.20, n 1, 1990. 
NOVAES, Regina. Os escolhidos de Deus: pentecostais, trabalhadores e cidadania. Cadernos do ISER, Rio de Janeiro, n. 19, 1985.

PIERUCCI, Antonio Flávio. De Olho na Modernidade Religiosa. Tempo Social, revista de sociologia da USP, v. 20, n.2, 2008.

PORTINARI, Natalia. VÍDEO: Eleitor Evangélico Tem Alta Expectativa Para Governo Bolsonaro. Época, 7 Nov. 2018. Disponível em:epoca.globo. $\mathrm{com} /$ video-eleitor-evangelico-tem-alta-expectativa-para-governo-bolsonaro-23211744. Acesso em: 30 jun. 2021.

ROCHA, João Cezar de Castro. Guerra cultural e retórica do ódio: crônicas de um Brasil pós-político. Goiânia: Editora e Livraria Caminhos, 2021.

ROLIM, Francisco Cartaxo. Pentecostais no Brasil: Uma Interpretação Sócio-Religiosa. Petrópolis: Vozes, 1985.

SANTOS, Lyndon de Araújo. O púlpito, a praça e o palanque: os evangélicos e o regime militar brasileiro. In: FREIXO, Adriano de; MUNTEAL FILHO, Oswaldo (Ed.). A ditadura em debate: Estado e sociedade nos anos do autoritarismo. Rio de Janeiro: Contraponto, 2005.

SPYER, Juliano. O povo de Deus: quem são os evangélicos e porque eles importam. São Paulo: Geração Editorial, 2020.

STEIL, Carlos Alberto; TONIOL, Rodrigo. A trajetória das ciências sociais da religião no Brasil e as diferentes perspectivas sobre o religioso. In: ALBUQUERQUE MARANHÃO, Eduardo Meinberg de (Org.). (Re) conhecendo o sagrado. Reflexóes teórico-metodológicas dos estudos de religióes e religiosidades. 1ed.São Paulo: Fonte editorial, p. 173-196, 2013.

VITAL DA CUNHA, Christina. Pentecostal cultures in urban peripheries: a socio-anthropological analysis of Pentecostalism in arts, grammars, crime and morality. Vibrant, v.15 n.1, 2018. 
VITAL DA CUNHA, Christina; LOPES, Paulo Victor Leite; LUI, Janayna. Religiāo e Politica: medos sociais, extremismo religioso e as eleiçôes 2014. Rio de Janeiro: Fundação Heinrich Böll: Instituto de Estudos da Religião, 2017. VITAL DA CUNHA, Christina. Oração de traficante: uma etnografia. Rio de Janeiro, Editora Garamond/ FAPERJ, 2015.

Recebido em: 28/05/2021

Aprovado em: 28/05/2021 

ENTREVISTA 
